\title{
OLOS BELANGKIT: A RESIDUAL SABAH TEXTILE TRADITION OF PAST CROSS-CULTURAL LINKAGES
}

\author{
Patricia Regis \\ Independent Researcher \\ (regis_trish092004@yahoo.com) \\ DOI: https://doi.org/10.22452/brj.sp2019no1.9
}

\begin{abstract}
This presentation describes a unique textile material culture peculiar to Sabah. Generically labelled as linangkit, it is a needle-work technique to create a narrow decorative but dense panel of fabric to join seams of traditional costumes and clothing. Production of this distinctive fabric is found concentrated on Sabah's north and west coast inhabited by producer and user indigenous groups comprising mainly of speakers of Dusunic, Sama-Bajau and Iranun languages. Invariably, the technique and product are called by a variety of names, each aligned to the respective producing indigenous groups and district: linangkit (Lotud, Tuaran), rinangkit, langkit (Rungus), olos belangkit (Bajau, Kota Belud), liangkitan (Iranun, Kota Belud). The olos belangkit of the Bajau of Kota Belud is significant for the panel's length and width; an extant but declining needle craft due to its painstaking process of creation. Semantics point to Mindanao as the source of this textile craft, and derivation of the term langkit (Maranao) which means lacework, ornamental or to decorate, and (Tausug) adjoin, and linangkit does all these. The cross-cultural linkages fostered by the mobile population plying between Sabah and Mindanao for centuries likely introduced the craft to Sabah where it is still a living heritage.
\end{abstract}

Keywords: cross-cultural linkages, tradition, textile, Olos Belangkit $\mathcal{E}$ Sabah

\section{Introduction}

This paper is based largely on research initially undertaken in 1991 during my tenure at the Sabah Museum. The research was part of a wider study on the traditional costumes and textiles of Sabah. It was noted that costumes and textiles were by far the most visible and attractive of Sabah's material cultural heritage. These costumes function more than just garments, with a variety of uses extending beyond social, psychological and economic objectives. Public demand for more information and a need for a comprehensive inventory of Sabah's indigenous costumes, textiles and motifs, origins and evolution prompted further research and documentation. What had been published so far had been fragmentary and tenuous, with many gaps in the 
museum record and inventory. A free-lance Dutch historian, Ms Madelon Boeye, supported by a grant from the Royal Netherlands Government over three months in 1993 assisted and coordinated the research on the costumes with Sabah Museum staff for a special costume exhibition. Alongside the research, costumes were also commissioned from selected master craftspersons, mostly elderly women. The initial collective efforts resulted in an exhibition of costumes and textiles in the Sabah which was opened in the Sabah Museum in May 1994. The display focused on selected textile and costume material culture of seven indigenous groups. This was followed by the book based on this collective research published a few years later (Lasimbang and Moo-Tan 1997).

Costumes, in particular, had also been evolving as they increasingly provided an important avenue, especially for indigenous minority groups to project and express a visible and tangible definition of their ethnic and cultural identity. Old forms usually are drawn from elders' memory supported by antiquated remnants of old costumes secreted as family heirlooms as a result were frequently resuscitated and given new life. Attempts to recreate and "replicate" these old forms have been achieved with variable levels of success, but not without, sometimes revolutionary reinvention and extensive refurbishment, usually in keeping with prevailing socio-cultural values and perceptions. These "new" designs were naturally embellished with more accessible and inexpensive modern and often conspicuous glittering trimmings and accessories intended to attract attention. The newer regenerations also reflect influences of acculturations of contiguous and dominant groups with more visible, striking and iconic costume and textile traditions. A salient example of such transformation would be the traditional female Tagal Murut attire - the existing long black ensemble of long skirt and blouse, with elaborate beaded embroidery and motifs has replaced, and in fact, barely resembles the original and traditional knee-length tubular skirt which was originally worn with the chest exposed. It was then, at the time an entirely acceptable form of female attire. The adornment of perhaps a necklace of one or few strands of heirloom and bridewealth beads provided perfunctory modest coverage. The gradual covering up influenced largely by greater society values of modesty progressed initially to the use of red cloth to cover the breast. The whole attire was then transformed to the predominant use of black cloth which has replaced previous fabrics of woven cloth with predominant reddish hues or commercial cotton cloth. With the successive additions and modifications, the new form has evolved and has become an established cultural attire, invariably bearing little resemblance to the old, as in the case of this "traditional" costume.

My principal interest in the study was the textile and needle craft phenomenon generically called linangkit in Sabah with dialect variations of the technique according to the language, districts of the user and producer groups. Accordingly. They are known as linangkit (Lotud, Tuaran), rinangkit, rangkit (Rungus), olos belangkit (Bajau, Kota Belud), liangkitan (Iranun, Kota Belud), but all refer to the distinct panel of dense 
fabric created through a complex needlework technique to join two seams of cloth. The olos belangkit of the Sama-Bajau of Kota Belud is an integral component of this heritage, and in this paper, it is described within the context of greater linangkit tradition in the State. Curiously, production is focused only in certain areas of Sabah. The form, i.e., the dense panel of fabric, has thrived and continues to be a distinct part of Sabah's living textile cultural heritage. However, like most other intensive manual labour craft manufacture its continuity as a unique traditional technique to produce the distinctive fabric as well as a fine artistic craft form is under serious threat. The painstaking process requiring immense patience and intense optical focus is such that few are willing to take on and continue these traditions, as labours of love and art. Most instead opt to concede to less laborious and time-consuming exertions and skills and substitutes not only to produce the costume product but also for speedier and greater financial returns.

\section{Historical antecedents}

Between 1995 and 1996 with a special research grant from the Toyota Foundation, I began a more profound exploration of this unique needle craft which occupies a prominent place in Sabah's traditional textile material culture. Semantics points to Mindanao as the source of this needle-craft. Linangkit appears to be a derivation of the term langkit (Maranao) which means lacework, ornamental or to decorate, and (Tausug) adjoin, and linangkit does all these, and it is what it means. The langkit produced by the Maranao and Maguindanao of Mindanao has similar objectives - a decorative strip to join two or more pieces of hand-woven cloth - only that it is hand woven on the loom. Some of the pre-historic hooks and lozenges motifs found in the Philippine langkit appear in Rungus hand-woven cloth but are devoid altogether in the Sabah linangkit inventory. The Maranao and adjacent ethnic communities including the Sama as well as the Tausug are indigenous to Mindanao and the Sulu islands. A very mobile population plying between Sabah and Mindanao for centuries fostered cross-cultural linkages and other social connections, notwithstanding the forced immigration through the active pirate and slave trade in the region, most likely introduced the craft to Sabah where it has continued as a living heritage. (Regis 199596, unpublished report)

The study necessarily took me to the southern Philippines to investigate the textile traditions there as semantics suggest the area as the historical antecedent of this needle-craft. Several trips made during the two years covered the cities and environs of Manila, Cagayan de Oro, Marawi, Zamboanga, Cotabato of Mindanao, and Jolo. But the needle-craft technique has all but disappeared in the Philippines; ephemeral traces of it were found finally, but only on a seam of a Yakan costume in public display at Nayong Filipino near the airport. The technique seems to have become obsolete in the Philippines, likewise on Sabah's east coast but still thrives on Sabah's west coast 
where it is called by variations of the root name, langkit. The Marano of Lanao del Sur still produce two types of langkit, but these are narrow tapestry woven cloth made on a special narrow loom to join three pieces of cloth together to form their traditional long tubular garment called malong. The narrow horizontal strips which join three panels of cloth is called tobiran, and the wider vertical lakban joins the two ends to form the malong. While the term malong has been retained by the Iranun to describe their sarong, construction of the motifs, designs and use of colours to create their liangkitan panels are quite different. The needle-weaving technique (described below) is used instead. Decorative motifs used in these panels are geometric patterns and stylised designs inspired by abstract elements of their environment and include plants and inanimate objects.

\section{Linangkit}

The linangkit functions as a traditional form of costume embellishment, and constitute an integral part of many of the older ceremonial attire of the groups inhabiting a distinct cultural corridor extending from west to the northern coasts of Sabah. Production of this distinctive fabric is confined to certain coastal indigenous groups on this coast and Kudat in the north with traditional links to the Philippines. These groups living contiguously within this corridor, appear to facilitate and strengthen material acculturation and reinforce continuity of this textile tradition among the producer and user groups. Each group has its traditional glossary of customary motifs and patterns, which can be further differentiated by the length and width of the panels. Among them is the Sama-Bajau of Kota Belud on the Tempasuk plains which produce a distinctive version of linangkit which they describe and label as olos belangkit or berangkit. Their adjacent neighbours are the Iranun and the Dusun Tindal who live on the plains, who share many similar textile and material culture traditions. Further south is the Lotud Dusun of the Tuaran District who was for a long time known as prolific producers of linangkit for their traditional costume assemblage. Further up north the Rungus Dusun of the Kudat and Pitas district produce longer and fine multicoloured narrow panels of rinangkit, rangkit and langkit which are definitive of their group. 

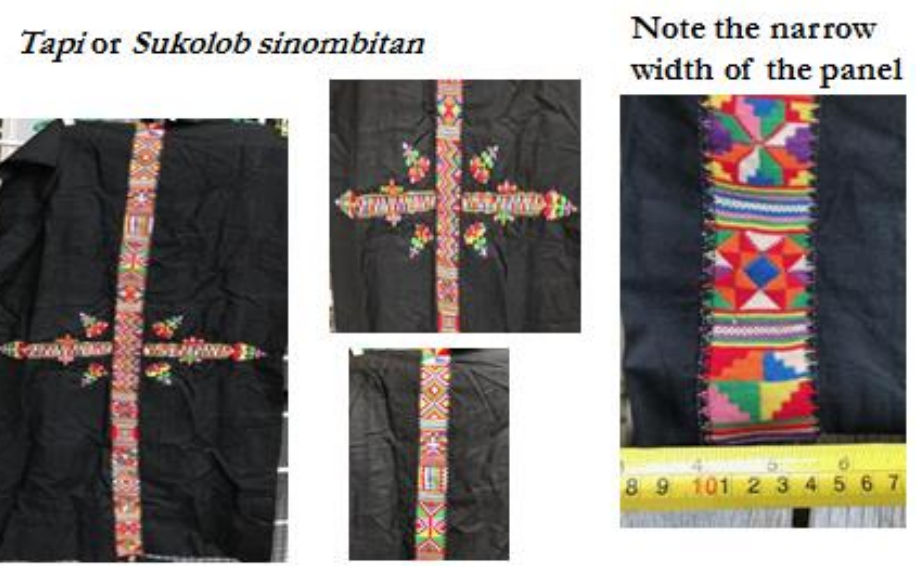

Figure 1: Rungus-Rinangkit, rangkit, also linangkit use warmer colours

(Source: Patricia Regis)

\section{A tapi (tubular skirt or sarong), patterns are worn at Close-up view of the back tinongkupan}
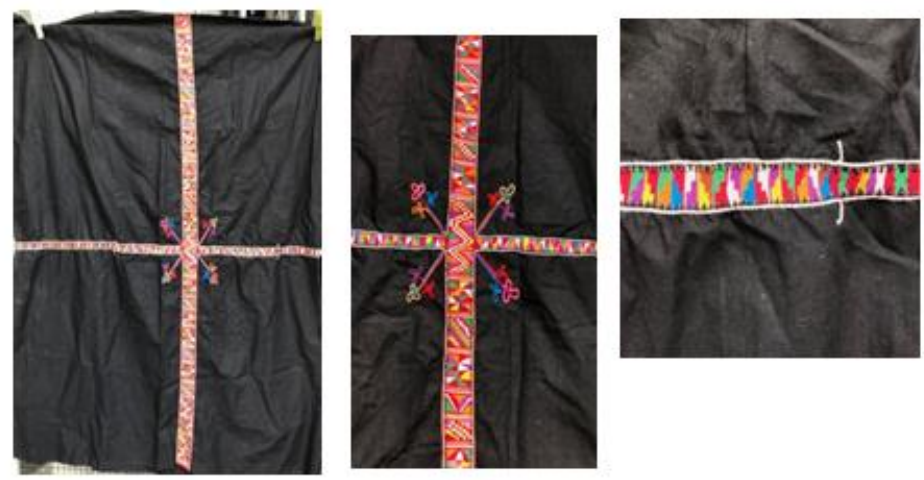

\section{Figure 2: Rungus-tinongkupan}

(Source: Patricia Regis)

Use of this needle craft as a decorative technique appeared to be more widespread in the past. The Kadazan women of the Papar District, south of Kota Kinabalu, once used linangkit to join the seams of their gonob or tapi ( their short circular sarong or tube), but that technique has fallen into disuse, displaced by preferences to use less difficult and less time-consuming cross-stitch embroidery imitations as substitutes. These, of course, require much less degree of skills and artistry. Nevertheless, they refer to these substitutes as linangkit, irrespective of the technique used, to describe the decorative vertical panel of their gonob or tapi. From a distance 
these cross-stitch substitutes resemble the traditional panel of the older gonob (sarong) as the producers and wearers of the costumes attempt to maintain the form and design to achieve the same visual effects, but these are fundamentally embroidery and not the fine intricate needle woven knot details of the older garments.

Use of linangkit to embellish and join garments has been traced as far as the hinterland of Tambunan and Keningau Districts according to informants. A crude form of linangkit was seen as a short a strip adjoining the seam of the ritual blouse of a female shaman at $\mathrm{Kg}$ Baru, Apin Apin, Keningau. However, the work was no way near the extant fine and delicate creations produced on the west coast.

\section{Construction of linangkit}

Linangkit is complex pieces of intricate and painstaking needle work that require considerable patience, skill and good_eye-sight_to create these complicated panels of fabric. A close equivalent would be the European technique of "tatting" or "frivolite", a French term. Tatting, however, produces a lace-like fabric while linangkit results in a panel of dense, strong fabric. In literature attempts to describe in English have defined linangkit generally as "needle weave" as well as "tapestry weave" using a pick similar to the crochet technique. But these descriptions, do not sufficiently explain how it is created as no loom, warp or weft threads are used in its construction. Linangkit uses needle and thread to create successive interconnecting and identical knots to form into a narrow panel of compact fabric which are used to decorate and join seams of garments and cloth.

Two lengths of usually black cloth placed equidistant from each other, sometimes pinned to a pad underneath, as a base to start the process. A series of interlocking knots are then constructed to form the fabric between the gap. The procedure gradually produces the definitive geometric patterns, a distinct feature of this textile. Variations occur in the width and length of the linangkit, and these are produced according to the traditional inventories of the respective indigenous groups. Important elements of the physical environment inspire most traditional motifs, and producer fabricates them into stylised geometric patterns. Each motif constructed can be replicated or repeated to form several adjoining segments to create the desired panel. Different coloured embroidery threads and several needles are used to create the variety and design needed. The width and length of the panel ultimately depend on the expertise and endurance of the maker. The wider, the lengthier and the finer the linangkit panel, the longer it would take to complete. 

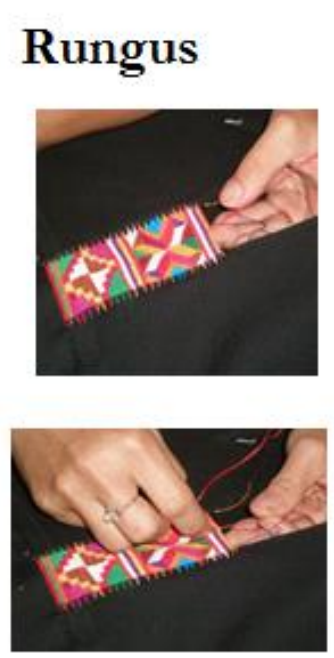

\section{Lotud}
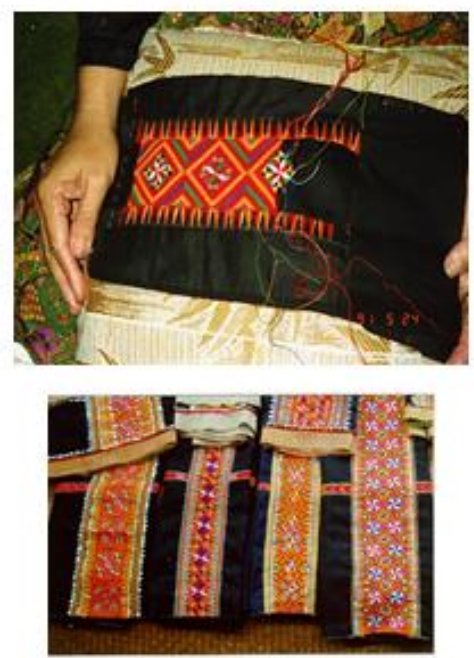

\section{Figure 3: Construction of a Linangkit, Rungus (left), Lotud (right)} (Source: Patricia Regis)

The fabric created through this technique is compact, sturdy and durable, and do not unravel easily. Fine pieces of linangkit are recycled for use on newer garments, as is often the case when the original one wears out over time.

\section{Master craftspersons}

The acknowledged masters of the linangkit are the elderly Lotud women folk on the Tuaran plains of Sabah's west coast, who are still prolific producers of the craft. It is an essential component of their male and female traditional and ceremonial costume, so outstanding that it has also become a definitive statement of their ethnic identity. They use primarily bright orange and red threads to create motifs of geometric patterns largely inspired by familiar natural and plant elements of their local environment in the linangkit produced for women's gonob (tubular skirt), kuluwu ( a circular shoulder scarf) and also men's trousers, binandus. A recurrent motif is the popular melon seed (inolinsausadur) and variants such as linodi (ritual offerings) and bininting (stars). The linangkit panels of the Lotud are generally short for the gonob with wider panels for the kuluwu. They raised the profile of linangkit which has become an established part of the iconic cultural imagery of Sabah's costume heritage.

The Rungus occupying the northern part of the cultural corridor call their version rangkit, or rinangkit, and linangkit also create distinct motifs in defined compartments, using warm and cooler coloured threads without any dominant hues. The inspiration for these motifs is derived from familiar objects, animals and plants 
found in their environment and daily life such as leaves, shells, butterflies, pythons and so on. These panels worn at the back are used to decorate the seams of the two types of sukolob, the tubular skirt or sarong tied above the breast. These are differentiated by the complexity of the needle work and embroidery - sinombitan, more elaborate versus tinongkupan, more plain. In the old days, extravagant linangkit patterns and motifs indicated the social position of the woman - with sinombitan she was likely the wife of the headman. Rinakit is also sewn on the back below the waistband of the men's trousers (soval sarabulu). Aside from the colours, the Rungus linangkit tend to be longer, but narrower, and also known for their delicate workmanship using finer yarn and thread.

\section{Olos Belangkit}

The Sama Bajau of Kota Belud, on the other hand, has a very rich repertoire of woven textile traditions. Along with their adjacent neighbours the Iranun they are prolific producers of hand-woven traditional cloth that is iconic to the state, and material culture heritage. Their women folk hand weave the traditional head cloths called kain podong (Bajau), or tubao (Iranun) called kain dastar (Malay) or sigah by the Kadazans and Dusuns that are worn by the men of almost all indigenous groups as their ceremonial attire. They also produce various hand-woven cloths including the distinctive textile called mogah which is also worn by other indigenous people. Outstanding and in constant demand for commercial and cultural needs these woven textile traditions have invariably overshadowed the more obscure and exceptional but equally significant olos belangkit or berangkit of the Sama Bajau of Kota Belud. The tedious and laborious process of its production has been its nemesis. For lack of producers and supply use of substitutes have become widespread as consumers and users turn to cheaper and commercially available alternatives and imitations. Form and appearance have overruled substance. However, the contrasting vertical panel in front of the olos or tube skirt is still referred to as belangkit, irrespective of how it is made. However, it is not the same. 


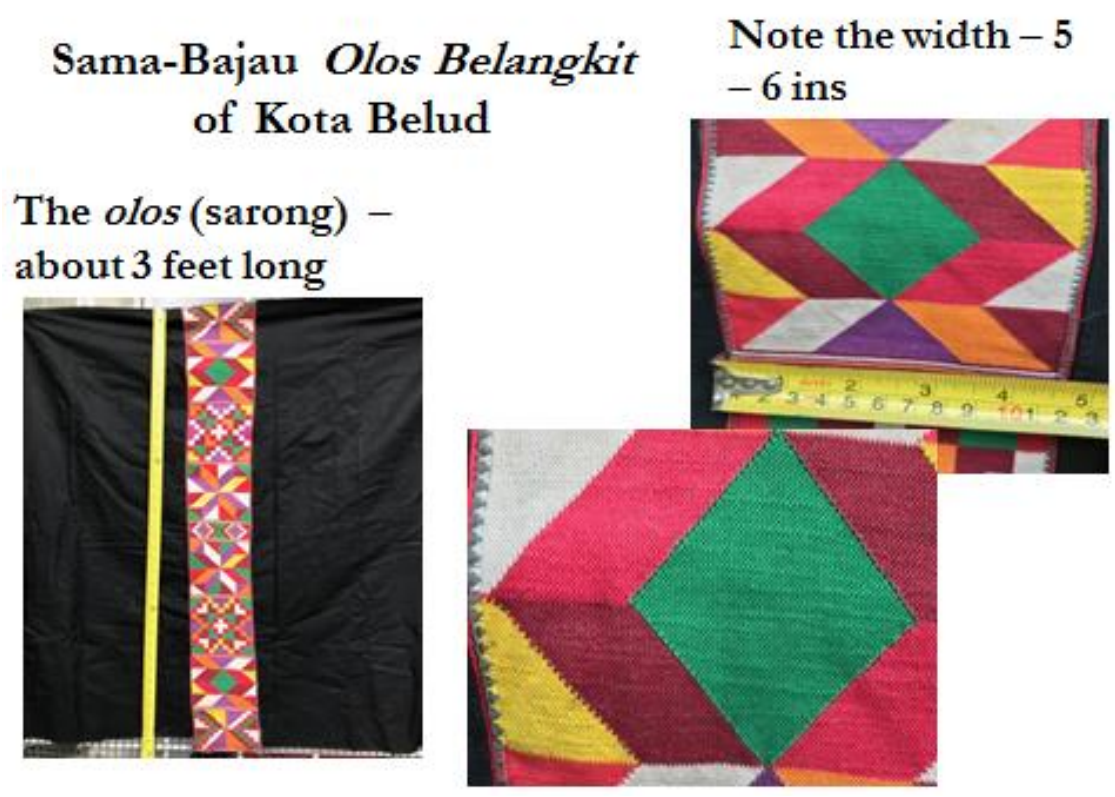

Figure 4: Sama-Bajau Olos Belangkit

(Source: Patricia Regis)

The traditional olos berangkit or belangkit is a full-length black wrap tubular ceremonial or matrimonial skirt with a wide vertical panel (berangkit) at the front usually featuring stylized motifs of the cotton flower (bunga kapas) or bamboo shoot (pucak rebung). The Sama Bajau of Kota Belud calls this needle craft to construct the olos berangkit or belangkit. As a verb, belangkit means to mesh and create the traditional motifs, mostly floral inspired. The Iranun, likewise, also produce liangkitan to decorate their malong, a similar long tubular piece of cloth which they use as a skirt or as a blanket. Compared to the other linangkit traditions the olos berangkit or belangkit is particularly significant by the unusual length and width of the panel. They are much longer, extending to three feet or more in length and may measure up to six inches wide. These are unusual and rare pieces. Motifs and patterns aside the linangkit of the other groups are generally shorter in length and rarely wider than 3 inches, with embroidered enhancements and embellishments flanking the seam that make these panels look wider.

\section{Summary}

Linangkit as a traditional craft art form appears to be a relic of past cross-cultural linkages with the southern Philippines where it is said to have originated. Trade and immigration fostered by the proximity of the two territories facilitate the cultural 
connections which continue to this day. This has differentiated Sabah's culture and demography from the rest of Borneo. Several elements in the forms, styles, as well as production techniques and nomenclature of Sabah's costumes and textile, appear similar to those seen in Mindanao.

"In transmigration from territory to other people invariably leave imprints of their respective cultures. Some remain dominant while others superimpose or assimilate with existing ones." (Regis, 1999)

Like many similar hand craft traditions, it appears to have fallen victim to competitive commercialised mass-produced substitutes to achieve immediate and desired objectives for defining traditional costumes and ready-made garments. Even in Sabah, the traditional and laborious process of production has placed this living heritage at considerable risk. Few, if any Sama-Bajau women are willing to learn and take on the challenges and the arduous manual task of producing the belangkit. A noticeable casualty in continuity appears to be the Sama-Bajau of Semporna, where the technique has completely disappeared in their textile and costume repertoire and assemblage. The current lack of viable inducements needs to be seriously addressed to counter competition of commercial imitations and financial motivations of other types of craftwork to ensure its continuity. High values comprising both financial incentives and recognition as well as elevation as a rare art form need to be instituted to encourage the younger generation to pursue and continue this tradition.

\section{ACKNOWLEDGEMENTS}

Many in Sabah and the Philippines contributed to the invaluable information and documentation of the linangkit tradition, not least my patient informants during fieldwork in Tuaran and Kota Belud. Fieldwork excursions also took me to Keningau, Tambunan and Papar to examine old and new costumes, and in the Philippines, museum libraries and costume collections, and private libraries, costumes exhibitions and humble homes of indigenous weavers. Among those who share in this documentation are several staff members of the Sabah Museum, Ms Madelon Boeye who coordinated the initial research, and Professor Jacqueline Pugh-Kitingan when she was a serving officer at the then Ministry Culture, Youth and Sports. My thanks to all.

\section{References}

Marion Pastor-Roces. (1991). Sinaunang Habi, Philippine Ancestral Weave. The Nikki Cosetang Filipiniana Series. 
Regis, P. (1995-1996). Motifs, Materials and Methods, The Philippines influence on Sabah Indigenous textiles and decorative techniques, unpublished report on the Linangkit following a two-year research and study (1995-1996) comparing indigenous textile traditions of Sabah with southern Philippines, to trace linkages and the ethno history through textile traditions of Sabah's indigenous peoples, supported by a grant from the Toyota Foundation.

Regis, P. (1995). Cultural Adaptation in Borneo: an overview of some aspects of material culture change in Sabah, in a monograph of the National Museum of Ethnology, Osaka, Japan.

Lasimbang, R. (1997). An introduction to the Traditional Costumes of Sabah, Eds. Rita Lasimbang and Stella Moo-Tan. Kota Kinabalu: Natural History Publications \& Department of Sabah Museum, Kota Kinabalu.

Regis, P. (1999). Linangkit, an echo of past regional affinities. Paper presented at East Asean Symposium on Culture and Folk Arts Festival: A BIMP-EAGA Joint Tourism Development Undertaking, Weaving our Futures together, The Living Fabric of EAST ASEAN Affinities, March 4-6, 1999, Malaybalay City, Bukidnon, Philippines.

Regis, P. (2002). Linangkit, A living Legacy of Past Regional Affinities. A paper presented at Borneo Research Council Seventh Biennial Conference, 15-18 July 2002, Kota Kinabalu. 